Journal of Engineering and Applied Sciences 15 (3): 783-788, 2020

ISSN: 1816-949X

(c) Medwell Journals, 2020

\title{
Densities, Viscosities and Excess Properties of Binary Liquid Mixtures of Methyl Tert-Butyl Ether (MTBE) with N-Methylaniline (NMA) from 308.15-318.15 $\mathrm{K}$ at 0.1 MPa
}

\author{
${ }^{1}$ Mohammed Rashid Ali, ${ }^{2}$ Firdos M. Abdulla and ${ }^{1}$ Noor Asma Fazli Abdul Samad \\ ${ }^{1}$ Faculty of Chemical andtural Resources Engineering, Universiti Malaysia Pahang, \\ Lebuhraya Tun Razak, 26300 Gambang, Pahang, Malaysia \\ ${ }^{2}$ Department of Chemical Engineering, University of Technology, \\ 10066 Baghdad, Iraq
}

\begin{abstract}
Densities and viscosities of binary liquid mixtures of Methyl Tert-Butyl Ether (MTBE) with N-Methylaniline (NMA) at temperatures of 308.15, 313.15 and 318.15 K have been measured experimentally at atmospheric pressure over the entire range of composition. The densities and viscosities of MTBE and NMA binary mixture show a decreasing trend with the increase in MTBE composition at all temperatures. In addition, Jouyban-Acree equation has been used to predict the densities and viscosities where low standard deviations of 0.0025 and 0.0168 have been obtained. The excess molar volumes and viscosity deviation have been calculated and correlated with the Redlich-Kister equation where a good fit was obtained. Sigmoid shape of excess molar volumes has been obtained where negative excess molar volumes were obtained at high mole fraction of MTBE for all temperatures. Negative viscosity deviation has been obtained which showed the strength of chemical interaction in terms of hydrogen binding between unlike molecules.
\end{abstract}

Key words: Density, viscosity, excess molar volume, viscosity deviation, methyl tert-butyl ether, $\mathrm{N}$-methylaniline, binary mixture

\section{INTRODUCTION}

The study of thermophysical properties of binary liquid mixtures is important in the analysis of engineering problems related to mass transfer, heat transfer and fluid flow (Cano-Gomez et al., 2015). The availability of the related data is essential in designing and solving many engineering problems such as process calculations, simulations and pipe design (Ramesh et al., 2014; Hoga and Torres, 2011). Usually, the density and viscosity of liquid and liquid mixtures are useful for understanding the behavior and nature of molecules (Hoga and Torres, 2011). In addition, the information of excess properties of binary liquid mixtures is also significant in order to study the intermolecular interactions between the components (Kumar and Jeevanandham, 2012; Hoga and Torres, 2011; Kinart and Kinart, 2000). Thus, the lack of thermodynamic data and molecular interactions for binary mixtures would lead to serious problems in phase behavior, molecular interactions, safety and economic considerations for chemical industries (Kinart and Kinart, 2000).

Usually, additives are used as blending agents for gasoline formulation in order to improve combustion and reduce the levels of soot as well as particulate emissions (Meng et al., 2008). Thus, research studies involving ethers and anilines as potential additives are actively performed. This is due to the fact that ethers as pure component or binary components with the combination of anilines is widely used due to its compatibility with gasoline and its ability to enhance the octane number, combustion improvement and emissions reduction (Hoga and Torres, 2011; Pandiyan et al., 2011; Saleh et al., 2001). Methyl Tert-Butyl Ether (MTBE) is one of the important blending agents for gasoline formulation (Han et al., 2013; Gomez-Marigliano et al., 2009). The main advantages of MTBE are good octane enhance and its capability to reduce exhaust emissions, particularly carbon monoxide (Gomez-Marigliano et al., 2009). Meanwhile, aniline is normally used for the manufacturing of chemical products such as the production of synthetic dyes, hydroquinone and drugs. Recently, the use of aniline compound such as N-Methylaniline (NMA) has been tested as fuel additives in gasoline direct injection engine (Nagano et al., 2017; Pandiyan et al., 2011).

Due to the importance of fuel additives, researchers have studied the various works of thermophysical properties. Densities and viscosities of binary mixtures MTBE with methanol, ethanol, 1-propanol, 2-propanol, 1-butanol, 1-pentanol and 1-hexanol have been determined at temperatures from 293.15-308.15 K

Corresponding Author: Noor Asma Fazli Abdul Samad, Faculty of Chemical and Natural Resources Engineering, Universiti Malaysia Pahang, Lebuhraya Tun Razak, 26300 Gambang, Pahang, Malaysia 
(Hoga and Torres, 2011). Excess thermodynamic properties of binary and ternary mixtures containing MTBE, n-heptane and methanol at a temperature of 313.15 K have been investigated by Segovia et al. (1999). Vapor-liquid equilibria and excess molar volumes of MTBE $+\mathrm{C}_{3}-\mathrm{C}_{4}$ alcohol systems at $298.15 \mathrm{~K}$ have been studied by Park et al. (2002). Densities, viscosities and refractive indices have been measured for binary mixtures of aromatic amines such as aniline and o-anisidine with 2-alkoxyethanols at $303.15 \mathrm{~K}$ (Kumar and Jeevanandham, 2012). Thermodynamic properties of seven binary liquid mixtures, namely, Dipropylene Glycol Dimethyl Ether (DPGDME)+ methanol, 1-propanol, 1-pentanol, 1-heptanol at 298.15 $\mathrm{K}$ and oxolane+aniline, NMA and N-Ethylaniline (NEA) from temperatures 303.15-321.15 $\mathrm{K}$ have been computed in the work of Sanguri et al. (2018). Oswal et al. (2010) reported the thermodynamic and acoustic properties of oxolane with aniline, NMA and NEA at 303.15, 313.15 and $323.15 \mathrm{~K}$. Densities, viscosities and ultrasonic sound velocities of NMA with methyl isobutylketone, 3-pentanone and cycloalkanones were measured at 303.15 K (Gowrisankar et al., 2013). Saleh et al. (2001) measured the excess molar volume of 1-propanol with aniline, NMA and N, N-dimethylaniline from 294.15-323.15 K.

Based on our review, there has yet to be an attempt on studying the densities, viscosities and excess properties of binary mixture MTBE+NMA. Thus, the objective of this study is to measure the densities and viscosities at three different temperatures: $308.15,313.15$ and $318.15 \mathrm{~K}$ under atmospheric pressure for binary mixtures of MTBE with NMA. This mixture is selected due to the fact that MTBE is mainly used in the industry as oxygenate additives in gasoline for improving the octane quality and reducing pollutant emissions. Meanwhile, NMA is added into gasoline to avoid high gum level that can contribute to the increment of carbon deposits in engine parts. In addition, the excess molar volumes and viscosity deviations are calculated from density and viscosity measurement data in order to analyze the nature of interaction between the molecules of the mixtures.

\section{MATERIALS AND METHODS}

Methyl Tert-Butyl Ether (MTBE) and N-Methylaniline (NMA) were purchased from Merck. The purity of all the chemicals was $>99 \%$ and they were used as received without further purification. The binary mixtures at varying compositions were prepared in terms of volume fraction. Before mixing the two liquids, the mass of the liquid volume is measured in an analytical electronic balance (Mettler ME203) with a precision of $1 \times 10^{-3} \mathrm{~g}$. Anton Paar DMA 4500 M Model was used for measuring the density for pure liquid and binary liquid. The oscillating U-tube sensor is equipped in the instrument and the investigated temperature was kept constant with the uncertainty of $\pm 0.01 \mathrm{~K}$ at $0.1 \mathrm{MPa}$. Viscosity was measured using Anton Paar Viscometer SVM 3001 which can be operated in the viscosity ranging from $0.2-30,000 \mathrm{~mm}^{2} \mathrm{sec}^{-1}$. The standard uncertainties for the density and viscosity werecalculated using a propagation error formula (Hall et al., 1975).

\section{RESULTS AND DISCUSSION}

The densities and viscosities of MTBE and NMA pure components are shown in Table 1 . The Average Absolute Precentage Deviations (AAPD) shown in Eq. 1 is used to determine the difference between the measured and experimental data of densities and viscosities.

$$
\mathrm{AAPD}=\frac{1}{\mathrm{n}}\left\{\sum \frac{\left|\mathrm{y}_{\mathrm{i}}^{\mathrm{exp}}-\mathrm{y}_{\mathrm{i}}^{\mathrm{cal}}\right|}{\mathrm{y}_{\mathrm{i}}^{\exp }} \times 100\right\}
$$

where, $y_{i}{ }^{\text {exp }}$ and $y_{i}{ }^{\text {cal }}$ are the experimental and literature densities and viscosities and $n$ is the number of experimental data points. AAPD of 0.27 and $1.24 \%$ have been obtained for densities and viscosities measurements, respectively. This indicates that the densities and viscosities data of the pure components measured in this work are relatively in agreement with the values reported in the literature.

\begin{tabular}{|c|c|c|c|c|c|}
\hline \multirow[b]{2}{*}{ Components } & \multirow[b]{2}{*}{ Temperature (K) } & \multicolumn{2}{|c|}{ Density, $\rho\left(\mathrm{gcm}^{-3}\right)$} & \multicolumn{2}{|c|}{ Viscosity, $\eta$ (MPa.s) } \\
\hline & & Experimental & Literature & Experimental & Literature \\
\hline \multirow[t]{3}{*}{ MTBE } & 308.15 & 0.723 & $\begin{array}{l}0.724^{\mathrm{a}} \\
0.726^{\mathrm{b}}\end{array}$ & 0.315 & $0.303^{\mathrm{b}}$ \\
\hline & 313.15 & 0.717 & $\begin{array}{l}0.720^{\mathrm{a}} \\
0.722^{\mathrm{b}}\end{array}$ & 0.283 & $0.284^{\mathrm{b}}$ \\
\hline & 318.15 & 0.714 & $\begin{array}{l}0.713^{\mathrm{a}} \\
0.718^{\mathrm{b}}\end{array}$ & 0.268 & $0.266^{\mathrm{b}}$ \\
\hline \multirow[t]{2}{*}{ NMA } & $\begin{array}{l}308.15 \\
313.15\end{array}$ & $\begin{array}{l}0.975 \\
0.971\end{array}$ & $\begin{array}{l}0.974^{\mathrm{c}} \\
0.970^{\mathrm{d}} \\
0.970^{\mathrm{c}}\end{array}$ & $\begin{array}{l}1.688 \\
1.564\end{array}$ & $\begin{array}{l}1.597^{\mathrm{e}} \\
-\end{array}$ \\
\hline & 318.15 & 0.966 & $0.966^{c}$ & 1.422 & - \\
\hline
\end{tabular}

a Landaverde-Cortes et al. (2007), 'Saleh et al. (2001), ${ }^{\mathrm{d} P a n d i y a n ~ e t ~ a l . ~(2011), ~}{ }^{\mathrm{e}}$ Prasad and Ray (2008) 
J. Eng. Applied Sci., 15 (3): 783-788, 2020

Table 2: Densities and viscosities at different temperatures and mole fractions for MTBE (1)+NMA (2)

\begin{tabular}{|c|c|c|c|c|c|c|}
\hline \multirow[b]{2}{*}{$\mathrm{x}_{1}\left(\mathrm{~mol} \mathrm{~mol}^{-1}\right)$} & \multicolumn{2}{|c|}{$\mathrm{T}=308.15 \mathrm{~K}$} & \multicolumn{2}{|c|}{$\mathrm{T}=313.15 \mathrm{~K}$} & \multicolumn{2}{|c|}{$\mathrm{T}=318.15 \mathrm{~K}$} \\
\hline & $\rho\left(\mathrm{gcm}^{-3}\right)$ & $\eta$ (MPa.s) & $\rho\left(\mathrm{gcm}^{-3}\right)$ & $\eta$ (MPa.s) & $\rho\left(\mathrm{gcm}^{-3}\right)$ & $\eta$ (MPa.s) \\
\hline 0 & 0.975 & 1.688 & 0.971 & 1.564 & 0.966 & 1.422 \\
\hline 0.086 & 0.959 & 1.491 & 0.951 & 1.359 & 0.947 & 1.237 \\
\hline 0.186 & 0.932 & 1.242 & 0.924 & 1.136 & 0.919 & 1.074 \\
\hline 0.276 & 0.909 & 1.080 & 0.899 & 0.994 & 0.895 & 0.951 \\
\hline 0.379 & 0.888 & 0.911 & 0.880 & 0.862 & 0.875 & 0.814 \\
\hline 0.480 & 0.864 & 0.814 & 0.852 & 0.743 & 0.848 & 0.679 \\
\hline 0.577 & 0.839 & 0.681 & 0.835 & 0.642 & 0.831 & 0.557 \\
\hline 0.688 & 0.806 & 0.550 & 0.804 & 0.525 & 0.799 & 0.432 \\
\hline 0.790 & 0.781 & 0.422 & 0.772 & 0.423 & 0.764 & 0.342 \\
\hline 0.903 & 0.754 & 0.349 & 0.749 & 0.331 & 0.744 & 0.303 \\
\hline 1 & 0.723 & 0.315 & 0.717 & 0.283 & 0.714 & 0.268 \\
\hline
\end{tabular}

Table 3: Coefficients of Jouyban-Acree Model for densities and viscosities prediction for MTBE+NMA binary mixture at different temperatures

\begin{tabular}{lcrrrr}
\hline Properties & Temperature $(\mathrm{K})$ & $\mathrm{J}_{0}$ & $\mathrm{~J}_{1}$ & \multicolumn{1}{c}{$\mathrm{J}_{2}$} & \multicolumn{1}{c}{${ }^{2}$} \\
\hline Densities & 308.15 & 3.1225 & 0.4447 & 2.2167 & 0.0019 \\
& 313.15 & 2.4696 & 2.4638 & 1.2312 & 0.0025 \\
Viscosities & 318.15 & 4.4453 & 3.6103 & -24.3377 & 0.0003 \\
& 308.15 & 9.5855 & -1.9427 & -12.6453 & 0.0168 \\
& 313.15 & 12.6631 & 12.8913 & -49.6668 & 0.0084 \\
\hline
\end{tabular}

The density and viscosity results for binary mixture of MTBE with NMA at temperatures of 308.15, 313.15 and 318.15 K are shown in Table 2. Overall, the densities of MTBE+NMA binary mixture had decreased with an increase in the MTBE composition and temperature. In terms of viscosity, it was observed that the viscosities decreased with the respective increment of the temperature. The decrement trend in densities and viscosities of MTBE+NMA is due to the fact that as the mole fraction of MTBE is increased, its binding with anilines decreased, producing a flow that is less dense, lighter, less viscous and easy in flow.

The densities and viscosities of MTBE+NMA binary mixture have been correlated using the Jouyban-Acree Model as shown in Eq. 2:

$$
\ln Q_{m, T}=f_{1} \ln Q_{1, T}+f_{2} \ln Q_{2, T}+f_{1} f_{2} \sum_{k=0}^{2}\left[\frac{J_{k}\left(f_{1}-f_{2}\right)^{k}}{T}\right]
$$

where, $\mathrm{Q}_{\mathrm{m}, \mathrm{T}}, \mathrm{Q}_{1, \mathrm{~T}}$ and $\mathrm{Q}_{2, \mathrm{~T}}$ are the properties of the binary mixture, pure component 1 and pure component 2, respectively at the investigated temperature. $f_{1}$ and $f_{2}$ are the volume fractions of the pure components 1 and 2. $\mathrm{J}_{\mathrm{k}}$ is the adjustable parameter for the given binary mixtures. The reliability of the model prediction is evaluated based on the standard deviations shown in Eq. 3:

$$
\sigma=\left[\frac{\sum_{\mathrm{i}=1}^{\mathrm{N}}\left(\mathrm{y}_{\mathrm{i}}^{\mathrm{exp}}-\mathrm{y}_{\mathrm{i}}^{\mathrm{cal}}\right)^{2}}{\mathrm{~N}-\mathrm{n}}\right]^{1 / 2}
$$

where, $\mathrm{N}$ is the number of experimental data points and $\mathrm{n}$ is the order of the fitting polynomial. The estimated coefficients using Jouyban-Acree Model for densities and viscosities prediction with their standard deviation are shown in Table 3. Based on the Jouyban-Acree Model, the standard deviation obtained for densities and viscosities prediction is $<0.0025$ and 0.0168 , respectively. Low standard deviation indicates that the predicted coefficients of the Jouyban-Acree Model are able to accurately predict the densities and viscosities of MTBE+NMA at different temperatures.

Other than density and viscosity, the excess properties of the binary mixtures such as excess molar volumes and viscosity deviation also provide important information regarding the strength of the molecular interaction present in the mixtures. The excess molar Volume $\left(\mathrm{V}^{\mathrm{E}}\right)$ of the binary liquid mixtures is calculated using the following equation:

$$
\mathrm{V}^{\mathrm{E}}=\mathrm{x}_{1} \mathrm{M}_{1}\left(\frac{1}{\rho}-\frac{1}{\rho_{1}}\right)+\mathrm{x}_{2} \mathrm{M}_{2}\left(\frac{1}{\rho}-\frac{1}{\rho_{2}}\right)
$$

where, $\mathbf{M}_{1}, \mathbf{M}_{2}, \rho_{1}$ and $\rho_{2}$ represent the molar masses and densities of components 1 and 2 and $\rho$ is the density of the liquid mixture. The viscosity deviation $(\Delta \eta)$ of the binary liquid mixture is defined by:

$$
\Delta \eta=\eta-\left(x_{1} \eta_{1}+x_{2} \eta_{2}\right)
$$

where, $\eta, \eta_{1}$ and $\eta_{2}$ are the dynamic viscosity of binary liquid mixture, components 1 and 2, respectively. The calculated excess molar volumes and viscosity deviations for MTBE+NMA binary mixture at different temperatures are shown in Table 4. In addition, Redlich-Kister equation is used to predict the excess molar volumes and viscosity deviation as shown in Eq. 6: 
J. Eng. Applied Sci., 15 (3): 783-788, 2020

Table 4: Excess molar volumes and viscosity deviations of MTBE+NMA binary mixture at temperatures of 308.15, 313.15 and $318.15 \mathrm{~K}$

\begin{tabular}{|c|c|c|c|c|c|c|}
\hline \multirow[b]{2}{*}{$\mathrm{x}_{1}\left(\mathrm{~mol} \mathrm{~mol}^{-1}\right)$} & \multicolumn{2}{|l|}{$\mathrm{T}=308.15 \mathrm{~K}$} & \multicolumn{2}{|l|}{$\mathrm{T}=313.15 \mathrm{~K}$} & \multicolumn{2}{|l|}{$\mathrm{T}=318.15 \mathrm{~K}$} \\
\hline & $\mathrm{V}^{\mathrm{E}}\left(\mathrm{cm}^{3} \mathrm{~mol}^{-1}\right)$ & $\Delta \eta$ (MPa.s) & $\mathrm{V}^{\mathrm{E}}\left(\mathrm{cm}^{3} \mathrm{~mol}^{-1}\right)$ & $\Delta \eta$ (MPa.s) & $\mathrm{V}^{\mathrm{E}}\left(\mathrm{cm}^{3} \mathrm{smol}^{-1}\right)$ & $\Delta \eta$ (MPa.s) \\
\hline 0 & 0 & 0 & 0 & 0 & 0 & 0 \\
\hline 0.086 & 0.58286 & -0.09900 & 0.72313 & -0.08491 & 0.88696 & -0.07582 \\
\hline 0.186 & 1.02900 & -0.19130 & 1.21494 & -0.17737 & 1.36512 & -0.15393 \\
\hline 0.276 & 1.00193 & -0.22922 & 1.20131 & -0.21660 & 1.28460 & -0.19264 \\
\hline 0.379 & 0.31608 & -0.24723 & 0.46726 & -0.23105 & 0.53970 & -0.21113 \\
\hline 0.480 & -0.33348 & -0.24468 & -0.44079 & -0.22786 & -0.57582 & -0.20884 \\
\hline 0.577 & -1.02801 & -0.23207 & -1.15087 & -0.21713 & -1.25872 & -0.19939 \\
\hline 0.688 & -1.56151 & -0.21376 & -1.71822 & -0.19903 & -1.97889 & -0.17637 \\
\hline 0.790 & -1.86364 & -0.18158 & -2.01505 & -0.15924 & -2.24366 & -0.14755 \\
\hline 0.903 & -1.51569 & -0.09904 & -1.62516 & -0.08613 & -1.78428 & -0.07682 \\
\hline 1 & 0 & 0 & 0 & 0 & 0 & 0 \\
\hline
\end{tabular}

Table 5: Coefficients of Redlich-Kister equation for excess molar volume and viscosity deviation of MTBE+NMA binary mixture at all temperatures

\begin{tabular}{|c|c|c|c|c|c|c|c|}
\hline \multirow[b]{2}{*}{$\underline{\text { Properties }}$} & \multirow[b]{2}{*}{ Temperature (K) } & \multicolumn{5}{|c|}{ Coefficients } & \multirow[b]{2}{*}{$\sigma$} \\
\hline & & $\mathrm{A}_{0}$ & $\mathrm{~A}_{1}$ & $\mathrm{~A}_{2}$ & $\mathrm{~A}_{3}$ & $\mathrm{~A}_{4}$ & \\
\hline \multirow[t]{3}{*}{ Excess molar volume } & 308.15 & -1.9599 & 14.8769 & 1.9876 & 0.8145 & -10.1520 & 0.0077 \\
\hline & 313.15 & -2.3191 & 16.4136 & 6.0479 & 1.3039 & -14.8516 & 0.0075 \\
\hline & 318.15 & -2.3764 & 18.5360 & 3.2203 & 1.6118 & -10.2361 & 0.0094 \\
\hline \multirow[t]{3}{*}{ Viscosity deviation } & 308.15 & -0.9035 & -0.4048 & -0.7896 & 0.6364 & 0.8970 & 0.0023 \\
\hline & 313.15 & -0.7766 & -0.4613 & -0.6518 & 0.2770 & 0.5385 & 0.0006 \\
\hline & 318.15 & -0.7682 & 0.3191 & -0.4744 & -0.6697 & 0.2487 & 0.0005 \\
\hline
\end{tabular}

$$
\mathrm{Y}_{\mathrm{m}}=\mathrm{x}_{1} \mathrm{x}_{2} \sum^{\mathrm{i}=\mathrm{n}} \mathrm{A}_{\mathrm{i}}\left(\mathrm{x}_{2}-\mathrm{x}_{1}\right)^{\mathrm{i}}
$$

where, $A_{i}$ are adjustable parameters that can be fitted with the experimental results using the least-squares regression method. The coefficients of Redlich-Kister equation for excess molar volumes and viscosity deviation at all temperatures are shown in Table 5, along with the standard deviation $(\sigma)$. Low standard deviations have been obtained for excess molar volume and viscosity deviation, indicating a reliable prediction has been obtained.

Figure 1 and 2 show the behavior of excess molar volume and viscosity deviation at all temperatures for MTBE+NMA binary mixture. Based on Fig. 1 and 2, it is clearly shown that the excess molar volume and viscosity deviation were successfully fitted using the estimated adjustable coefficients for Redlich-Kister equation. For excess molar volume, it can be seen that the sigmoid curves have been obtained for MTBE+NMA binary mixture as shown in Fig. 1. The excess molar volumes are positive at low mole fractions of MTBE while it became negative when the mole fraction of the binary mixture is more than 0.44. Both positive and negative values were observed to increase with an increase in temperature over the entire composition. At low mole fraction of MTBE, positive excess molar volumes are obtained due to the expected dispersive interaction force between the unlike two molecules (Hoga and Torres, 2011). Since, only a single methyl group is attached to atom $\mathrm{N}$ in the NMA component, it can be suggested that less extensive associated of methyl group through $\mathrm{H}$ bonding is expected due to the more steric hindrance by the methyl group that is attached to the NMA. However in the MTBE rich region, negative

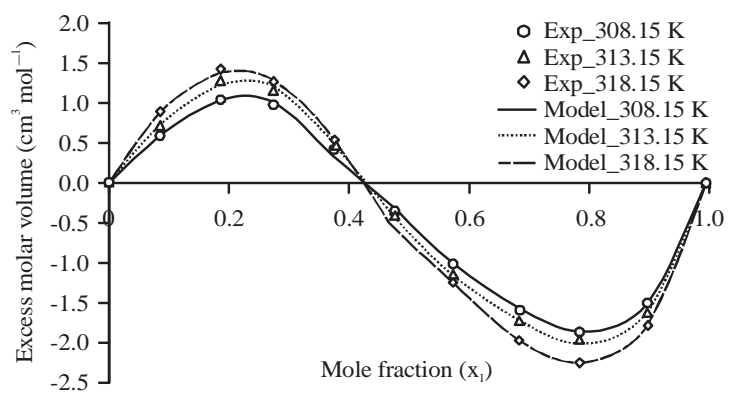

Fig. 1: Excess molar volumes for MTBE+NMA binary mixture for all temperatures

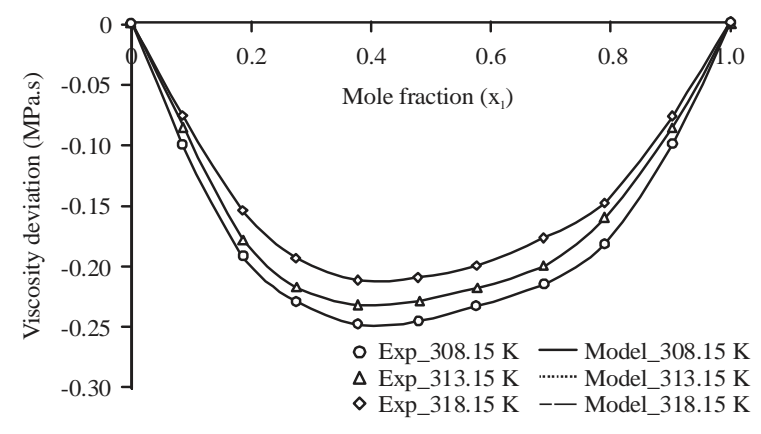

Fig. 2: Viscosity deviations for MTBE+NMA binary mixture for all temperatures

excess molar volumes are obtained. This may be attributed to the strong specific or chemical interactions between MTBE and NMA. As the composition of the MTBE increased, the molar volumes of MTBE also increased in which the MTBE becomes superior to NMA. Consequently, the mixture containing ether and aniline 
group for MTBE+NMA will associate with the hydrogen bonding due to structural effects. Thus, a more efficient packing and attractive interaction takes place when MTBE and NMA aremixed, leading to the negative excess molar volume. In terms of viscosity deviations, negative values are obtained for MTBE+NMA for all temperatures but they become less negative with an increase in temperatures from 308.15, 313.15 and $318.15 \mathrm{~K}$ as shown in Fig. 2. The viscosity of the liquid mixture is usually determined by many factors which may include the structure of the molecules, effectiveness of the intermolecular binding forces and thermal energy (Oswal et al., 2010). Dubey and Kumar (2016) stated that in addition to the intermolecular interaction, the shape and size of the molecules may also influence the value-sign and range of the viscosity deviation. They have also found that the negative deviation observed at entire composition range may be attributed to the strength of chemical or specific interaction such as hydrogen binding between the unlike molecules. Thus, it can be concluded that the negative deviations for MTBE+NMA binary mixture indicate the inclusion of small molecules of NMA in the structure of larger molecules such as MTBE. This suggests the breaking up of the self-associated aniline group in NMA components into MTBE molecules.

\section{CONCLUSION}

In this study, the densities and viscosities of MTBE+NMA are measured experimentally at temperatures between 308.15 and $318.15 \mathrm{~K}$. As the MTBE composition is increased, the densities and viscosities of MTBE+NMA decreased at all temperatures. Jouyban-Acree Model is used to predict the densities and viscosities where a good agreement has been obtained between the experimental and prediction values. Meanwhile, the Redlich-Kister equation is used for predicting excess molar volumes and viscosity deviation where low standard deviations of 0.0094 and 0.0023 were obtained, indicating a well-fitted predictive model. In terms of the trends, the excess molar volumes at all temperatures for MTBE+NMA have changed from positive to negative values when the MTBE composition is increased. This indicates the strength of interaction between the unlike molecules obtained. The negative viscosity deviation is obtained for the MTBE+NMA binary mixture which indicates the inclusion of small molecules of NMA into MTBE molecules.

\section{REFERENCES}

Cano-Gomez, J.J., G.A. Iglesias-Silva, E.O. CastrejonGonzalez, M. Ramos-Estrada and K.R. Hall, 2015. Density and viscosity of binary liquid mixtures of ethanol+1-hexanol and ethanol+1-heptanol from (293.15 to 328.15) $\mathrm{K}$ at 0.1 MPa. J. Chem. Eng. Data, 60: 1945-1955.
Dubey, G.P. and K. Kumar, 2016. Interaction studies in binary liquid mixtures of ether and Alcohols at different temperatures. Indian J. Chem., 55A: 1314-1324.

Gomez-Marigliano, A.C., A. Arce, E. Rodil and A. Soto, 2009. Isobaric vapour-liquid equilibria at 101.32 $\mathrm{kPa}$ and densities, speeds of sound and refractive indices at $298.15 \mathrm{~K}$ for MTBE or DIPE or TAME+1-Propanol binary systems. J. Chem. Eng. Data, 55: 92-97.

Gowrisankar, M., P. Venkateswarlu, K. Sivakumar and S. Sivarambabu, 2013. Ultrasonic studies on molecular interactions in binary mixtures of $\mathrm{N}$-methyl aniline with Methyl isobutylketone, +3-Pentanone and +Cycloalkanones at 303.15K. J. Solution Chem., 42: 916-935.

Hall, K.R., D.J. Kirwan and O.L. Updike, 1975. Reporting precision of experimental data. Chem. Eng. Educ., 9: 24-30.

Han, K., S. Xia, P. Ma, F. Yan and T. Liu, 2013. Measurement of critical temperatures and critical pressures for binary mixtures of Methyl Tert-Butyl Ether (MTBE)+Alcohol and MTBE+Alkane. J. Chem. Thermodyn., 62: 111-117.

Hoga, H.E. and R.B. Torres, 2011. Volumetric and viscometric properties of binary mixtures of \{Methyl Tert-Butyl Ether (MTBE)+Alcohol $\}$ at several temperatures and $\mathrm{p}=0.1 \mathrm{MPa}$ : Experimental results and application of the ERAS model. J. Chem. Thermodyn., 43: 1104-1134.

Kinart, C.M. and W.J. Kinart, 2000. Physicochemical methods used to study internal structures of liquid binary mixtures. Phys. Chem. Liq., 38: $155-180$.

Kumar, S. and P. Jeevanandham, 2012. Densities, viscosities, refractive indices and excess properties of aniline and $\mathrm{O}$-anisidine with 2-alkoxyethanols at 303.15 K. J. Mol. Liq., 174: 34-41.

Landaverde-Cortes, D.C., A. Estrada-Baltazar, G.A. Iglesias-Silva and K.R. Hall, 2007. Densities and viscosities of MTBE+Heptane or Octane at $\mathrm{p}=0.1 \mathrm{MPa}$ from (273.15 to 363.15) K. J. Chem. Eng. Data, 52: 1226-1232.

Meng, X., J. Wu and Z. Liu, 2008. Viscosity and density measurements of Diisopropyl ether and Dibutyl ether at different temperatures and pressures. J. Chem. Eng. Data, 54: 2353-2358.

Nagano, S., N. Yokoo, K. Kitano and K. Nakata, 2017. Effects of high boiling point fuel additives on deposits in a direct injection gasoline engine. SAE. Intl. J. Fuels Lubr., 10: 789-802. 
Oswal, S.L., V. Pandiyan, B. Krishnakumar and P. Vasantharani, 2010. Thermodynamic and acoustic properties of binary mixtures of oxolane with aniline and substituted anilines at 303.15, 313.15 and 323.15 K. Thermochim. Acta, 507: 27-34.

Pandiyan, V., P. Vasantharani, S.L. Oswal and A.N. Kannappan, 2011. Thermodynamic and acoustic properties of binary mixtures of ethers. 2. Diisopropyl ether with arylamines at (303.15, 313.15 and 323.15) $\mathrm{K}$ and application of eras model to aniline mixtures with Diisopropyl ether and oxolane. J. Chem. Eng. Data, 56: 269-277.

Park, S.J., K.J. Han and J. Gmehling, 2002. Vapor-liquid equilibria and excess properties for Methyl Tert-Butyl Ether (MTBE) containing binary systems. Fluid Phase Equilib., 200: 399-409.

Prasad, N. and R.P.K. Ray, 2008. Excess free volumes and internal pressures of binary solutions of N-butanol and anilines. J. Pure Appl. Ultrasonics, 30: 31-41.
Ramesh, R., A. Hisyam, A.Z. Sulaiman and K. Ramesh, 2014. Measurement and predict thermo physical properties of binary liquid mixtures at various temperatures using Redlich-Kister model. Chem. Eng. Sci., 2: 18-23.

Saleh, M.A., M. Alauddin and S. Begum, 2001. Excess molar volume of 1-Propanol+Aniline, $+\mathrm{N}$-methylaniline, $+\mathrm{N}, \mathrm{N}$-dimethylaniline. Phys. Chem. Liq., 39: 453-464.

Sanguri, V., R. Sethi and J.D. Pandey, 2018. Thermodynamic and interaction studies of binary liquid mixtures on the basis of Florys Statistical theory and empirical relations. J. Mol. Liq., 271: 892-906.

Segovia, J.J., M.C. Martin, C.R. Chamorro and M.A. Villamanan, 1999. Excess thermodynamic properties of binary and ternary mixtures containing methyl 1, 1-Dimethylethyl ether (MTBE), N-Heptane and Methanol atT=313.15 K. J. Chem. Thermodyn., 31: 1231-1246. 